\title{
O Brasil em miniatura de Cyro dos Anjos
}

Ana Paula Franco Nobile Brandileone Universidade Estadual do Norte do Paraná

Resumo: A ficção brasileira da década de 1930 assistiu a um movimento de polarização ideológica e literária rígida, que reduziu os escritores a dois blocos estanques: o dos que faziam romance social e o dos que escreviam romance psicológico. Por não evidenciar uma estética literária participante, $\mathrm{O}$ amanuense Belmiro, de Cyro dos Anjos (1937), foi logo entendido pela critica de primeira hora como um romance puramente intimista. A fim de mostrar que o autor não era, absolutamente, alienado aos problemas do seu tempo, este artigo tem como objetivo pôr em destaque o substrato histórico do romance.

Palavras-chave: Cyro dos Anjos, $\mathrm{O}$ amanuense Belmiro, Revisão crítica, Tensão histórica. 


\section{Recepção crítica: Cyro dos Anjos e a tradição literária mineira}

Quando, em outubro de 1937, Cyro dos Anjos estreou na ficção brasileira, houve aceitação imediata do romance. Na primeira edição, $O$ amanuense Belmiro recebeu a marca da Sociedade Editora Amigos do Livro, uma espécie de coeditora, com número limitado de sócios, e cujas edições eram pagas pelos próprios autores. A primeira tiragem, de apenas 1.500 exemplares foi, em parte (500 exemplares), distribuída pela Editora José Olympio. Tamanha foi a repercussão que, dez meses depois, o romance conquistou uma segunda edição, numa tiragem mais numerosa, sob a chancela da própria José Olympio. Foi lançado simultaneamente no Rio, São Paulo, Bahia, Recife, Porto Alegre e Belo Horizonte. Mais tarde, além das inúmeras reedições, o livro também foi traduzido para o espanhol, italiano, inglês, francês e ganhou, ainda, uma edição para Portugal. ${ }^{1}$

Havia grande expectativa por ocasião do lançamento do romance. O fato de o romance ter sido gerado a partir de crônicas que Cyro dos Anjos escreveu para A Tribuna e o Estado de Minas entre 1933 e 1935, sob o pseudônimo de Belmiro Borba, fez nascer no público e na crítica a curiosidade do que sairia das entranhas do escritor mineiro. Como existia certa continuidade temática entre as crônicas, amigos e leitores pensavam que se tratava de capítulos soltos de um futuro romance e, muitas vezes, cobravam de Cyro o romance que ele não estava escrevendo:

Homem de letras sem obras publicadas, nos jornais em que trabalhou, cometeu a imprudência de usar pseudônimos. O nome de Belmiro Borba, em O amanuense Belmiro, é uma reivindicação. O livro estava prometido para o público há anos. O livro de Cyro dos Anjos era uma pilhéria. Por isso, até agora o autor figurou nos meios literários com matrícula condicional, mediante compromisso de apresentar os documentos. Eis, afinal, os documentos.

1. El amanuense Belmiro. México (DF): Tezontle, 1954; Carnevale a Belo Horizonte. Milano: Fratelli Bocca Editori, 1954; O amanuense Belmiro. Lisboa: Livros do Brasil, 1955; Diary of a Civil Servant. Cranbury: Associated University Presses, 1988; Belmiro - Belo Horizonte, 1935. Paris: A. M. Métailié, 1988.

2. Com o fechamento de A Tribuna, em 1933, Cyro dos Anjos continuou escrevendo suas crônicas no Estado de Minas.

3. SILVA. Cyropédia, [s.p.]. 
Livre das estafantes tarefas burocráticas, o romance saiu em quarenta dias, durante uma temporada de Benedito Valadares, de quem Cyro era assessor na época, e de Getúlio Vargas, em Poços de Caldas. As condições favoráveis permitiram que Cyro dos Anjos se debruçasse sobre o livro que lhe estavam exigindo. As páginas escritas à mão, noite adentro, eram datilografadas de manhã por pessoas amigas e revistas à tarde. Durante esse tempo dormia mal, comia às pressas e tinha pesadelos com os seus personagens:

No palácio (o da Capital), eu tinha datilógrafa à disposição. Resolvi escrever o livro, que estavam me cobrando. Eu tinha as crônicas, tinha o personagem, tinha o caráter do personagem. Havia a conjunção favorável de fatores, disponibilidade de tempo e disponibilização de espírito. Eu escrevia de madrugada, tomando conhaque de São João da Barra e café requentado. Foi uma coisa quase mediúnica. Embora eu seja lerdo de escrever, O Amanuense fluiu com grande espontaneidade.

A despeito de o público estar predisposto para uma modalidade de romance em que predominavam os aspectos exteriores - sendo a maioria dos personagens sem densidade psicológica, sem conflitos de consciência -, as descrições abundantes e a denúncia social, O amanuense Belmiro foi recebido, àquela altura da década de 1930, como a estreia mais significativa do ano: "[...] o romance é digno de figurar entre os melhores que ultimamente têm publicado os intelectuais brasileiros"; "[...] os generais da crítica não só da capital, mas de todo país já se manifestaram, com elogios rasgados, sobre o livro de Cyro dos Anjos[, que] se tornou um dos mais perfeitos romancistas do Brasil moderno"; "O amanuense Belmiro representa alguma coisa de definitivo, no campo deste tão limitado gênero narrativo".

Segundo o próprio escritor em entrevista concedida a Afonso Henrique Fávero, o bom acolhimento do romance deveu-se ao esgotamento da memória social nordestina que, por apresentar as mesmas paisagens, os mesmos climas, os mesmos problemas, exauriu-se:

4. ANJOS. Cyro aos 70, [s.p.].

5. VIANA. O amanuense Belmiro, [s.p.]. Artigo publicado posteriormente com outro título, não constando o nome do autor: "A Hora do Brasil elogia um brilhante escritor mineiro".

6. MONT'ALVÃO. O jornalista Cyro dos Anjos e o seu romance, [s.p.].

7. BERNARDES FILHO. O amanuense Belmiro, [s.p.]. 
Quando surgiu O amanuense, havia um cansaço da literatura nordestina, do homem do campo, do ciclo do açúcar; aliás, com grandes escritores como Graciliano Ramos e José Lins do Rego. O meu livro veio com outro espírito; é um livro intimista, pelo menos pretensamente psicológico, de maneira que ofereceu um outro tipo de literatura na ocasião e realmente ele foi acolhido com muita simpatia.

Prova desse enfraquecimento da literatura de temática social é um artigo publicado em dezembro de 1937, por Ayres da Mata Machado Filho, que afirma ter a novelística social de 1930 caído na mesmice. Segundo ele, os romances documentários, vazados de acusação aberta, de testemunho, já causavam tédio. Reclamando por uma literatura que devolvesse às Letras Brasileiras a noção de universalidade, que restaurasse o verdadeiro sentido do romance, o crítico declara:

Estamos positivamente enfarados da objetividade procurada de certos romancistas nacionais. $\mathrm{E}$ a tal ponto que as reclamações de críticos e leitores já se tornaram enfadonhas, à força de repetidas. Não seriam agora cabíveis a propósito do romance de Cyro dos Anjos [...]

O empenho em reconstruir ambientes típicos é que tem sido a preocupação moderna. E na verdade já estamos cansados dos romances sobre isto ou aquilo. Leitor de novelas e monografias, penso que o verdadeiro romance é como a vida: não tem finalidade nem motivo prévio. Ressalvadas as linhas comuns das verdades metafísicas, que - essas sim distinguem o personagem do boneco que sabe chorar - na despreocupação de objetivos e planos fatais está o segredo da verdadeira criação de romancista.

Não se deixando, portanto, impregnar nem pela "moda" nem pela imposição editorial do momento, Cyro dos Anjos revelou o "verdadeiro caminho da cultura", devido ao apego ao "essencial" e aos "verdadeiros valores", segundo Oscar Mendes:

Não é um livro da moda. Não se veste com os figurinos que certos editores impõem, dando a entender que a exigência de certos trajes estrambólicos parte do público, quando na realidade não passa de uma perversão do gosto de certo público que não tem noção do essencial e dos verdadeiros valores.

8. FÁVERO. A prosa lírica de Cyro dos Anjos, p. 148.

9. MACHADO FILHO. O amanuense Belmiro e sua novidade, [s.p.]. 
Não faz questão de aparecer de tanga num salão de baile para escandalizar moças e provocar piadas apimentadas dos rapazes. Prefere a velha decência das roupas limpas e saudáveis, sem complicação nem excentricidades de "leão de moda", mas cômodas e discretas.

E é como representante da "turma mineira" que, segundo a crítica literária de primeira hora, Cyro dos Anjos soube reagir contra os princípios mais evidentes do romance social - o enfoque documental sobre a vida dos humildes, o engajamento, a denúncia e a obsessão fotográfica e documental -, e firmar-se sobre um mundo construído na introspecção:

A turma mineira, dizia-me outro dia Graciliano Ramos, é a maior e a mais sólida de todas. Realmente o que caracteriza as figuras literárias mineiras é uma força e um equilíbrio que nenhuma outra frente possui. Jamais fizeram regionalismo partidário ou partidarismo literário [...] sua concepção é mais ampla, mais universal, tem o verdadeiro sentido da arte [...] e ao qual está destinada um papel importantíssimo de reequilíbrio da nossa literatura tão descorçoada nos últimos tempos pelo amor do modismo, que é sempre o amor da glória fácil. ${ }^{11}$

Guardar a tradição literária mineira traduz não só a inclinação psicológica, o lirismo comedido, a tendência para espiritualizar os valores da vida, das coisas e dos seres humanos e o apego a ideias e rumos universais - por isso, a ausência do realismo objetivo, da descrição minuciosa de ambientes e das sugestões da natureza -, mas também o apreço pela clareza, pela correção e precisão linguísticas, o que configuraria uma reação do Centro contra a "língua estropiada" dos romances do Norte:

Se há, como notam os observadores do movimento literário do Brasil, uma reação do centro e, particularmente, de Minas contra os romances em voga na atualidade, essa reação deve ser no sentido do equilíbrio, da boa norma clássica, da exata propriedade do vocábulo, da serena análise dos sentimentos ou das idéias [...] É por isso, certamente, que o romantismo - que não passa de uma floração romântica, a atual ficção

10. MENDES. A alma dos livros, [s.p.].

11. REBELLO. Figuras mineiras, [s.p.]. Esse artigo foi publicado posteriormente com outro título, não constando o nome do autor: "Cyro dos Anjos e o êxito de O amanuense Belmiro". 
literária nordestina - nunca armou, de fato, as suas tendas em Minas. São, pois, justas as esperanças que os observadores da vida literária nacional depositam em Minas [...] Minas está em condições de dar às nossas letras um período áureo. Se há necessidade de uma reação contra o neo-romantismo que vai estropiando nossa língua, essa reação já partiu das montanhas. ${ }^{12}$

A "direção diferente" empreendida por Cyro dos Anjos, porque herdeiro da tradição literária de Minas Gerais, concorreu para que fosse classificado como um escritor intimista. Num momento em que as direções eram compreendidas como estanques, de um lado romances que "se escravizaram ao empenho fotográfico da objetividade", de outro, romances em que "o principal é o homem" "13 aceitar um deles era, automaticamente, afastar-se do outro. Exemplo dessa polarização literária e ideológica que caracterizou a ficção de 1930 é um artigo de Josué Montello:

É claro que chamo de grande romancista a Cyro dos Anjos apenas no sentido do romance introspectivo. Mesmo porque do outro lado, eu teria que citar um Jorge Amado, um Lins do Rego, que ainda romanceiam a vida nos seus espetáculos externos.

Não por acaso, obras com o feitio de O amanuense foram acusadas de se alienar dos problemas sociais brasileiros ou, antes, "dar-se ao luxo das abstrações" ${ }^{15}$

A ideia de classificar a ficção brasileira de 1930 em uma ou outra direção é fácil. Fixar separações enormes entre escritores é pacífico. Mas como classificar O amanuense Belmiro se ele, ao mesmo tempo em que se opõe à tendência regionalista pelo seu caráter psicológico/introspectivo, aproxima-se da tendência crítica do momento?

Alegoria dessa discussão é um trecho do capítulo 40, intitulado "Choques", no qual Redelvim pressiona Belmiro por uma definição política. Diante da pergunta "Que é que você é, na ordem das coisas?", ele reage apontando para a dificuldade em se chegar a definições rigorosas:

As idéias da gente podem não comportar-se dentro dessas divisões arbitrárias. Não é possível ser-se tudo, ao mesmo tempo? E, se sentimos que a verdade e a contradição foram semeadas em todos os campos, como

12. LIVROS Novos, [s.p.].

13. CAMILLO. O amanuense Belmiro de Cyro dos Anjos, [s.p.].

14. MONTELLO. O livro nacional, [s.p.].

15. AMADO. Impressões de um clima e dois romances, [s.p.]. 
podermos definir-nos? Tudo o mais é violência ao espírito [...] O que é injusto é extorquir de nós uma definição, quando a procuramos, em vão, sem a encontrarmos $[\ldots]^{16}$

Assim como Belmiro recusa-se em comportar-se, ideologicamente, dentro de divisões arbitrárias, também não é possível compartimentar, classificar o romance de Cyro dos Anjos, pois o seu esquema não é das polarizações radicais.

Flagrante de uma "outra" e "nova" maneira de ler O amanuense Belmiro é o artigo de Antonio Motta do Valle que, em janeiro de 1938, já apontava para exploração do especificamente brasileiro, revelando "a mesma raiz de tragédia brasileira" dos romances cíclicos de José Lins do Rêgo. Para Motta do Valle, ${ }^{17}$ a afinidade "[...] entre essas duas expressões do romance nacional está nos personagens centrais, nesse tipo de raça, de rural decaído", pois neles se escondem o drama "[...] da industrialização, da emigração urbana e da decadência do patriarcalismo rural". ${ }^{18}$ Também João Etienne Filho, em artigo publicado em outubro de 1945, põe em xeque esse viés estanque da ficção de 1930, alertando que "passa por ridículo" aquele que ainda acusar Cyro dos Anjos de "escritor gratuito", porque o romancista mineiro "[...] a seu modo, participa também da realidade, do movimento, do espaço, e vai dando o seu testemunho, lá a seu jeito":

Aparentemente, o seu livro não participa, não tomou partido do povo, para usar uma expressão tão elevada, mas que toma o ar detestável à custa de ser explorada em campanhas políticas nem sempre muito honestas. O primeiro livro nos narra as desventuras de um pobre amanuense, cheio de dramas, às voltas com uma turma de literatos, amando a um mito, vivendo entre duas irmãs esquisitíssimas, escrevendo seu diário lírico. De fato, nada de mais aparentemente gratuito, inócuo. Passado o tempo, porém, voltemos ao amanuense. Como resiste bem a estes nove anos de vida. Como encontramos ali uma sociedade, um clima. Como a "situação" histórica está fixada por processos sutis da arte. Em toda uma classe miseravelmente desamparada que é fixada em Belmiro. É todo um mundo pequeno-burguês que se move ao seu redor. O que há apenas é o seguinte: o livro não quis ser documental, não foi feito com a intervenção de servir para arte social, no mau sentido em que tomamos essa expressão. Como toda a grande obra, aliás, que quase nunca é feita com o caráter específico

16. ANJOS. O amanuense Belmiro, p. 86.

17. VALLE. Crônica do amanuense, [s.p.].

18. Sobre esse tópico, ver ensaio: BRANDILEONE. Cyro dos Anjos: uma nova estreia. 
de documento, de prova, de testemunho, mas que, justamente por isto, fica com melhor documento, a melhor prova, o melhor testemunho.

O fato de Cyro dos Anjos ter inscrito as pautas da realidade nacional na fatura literária, a partir da qual interiorizou e dramatizou a estrutura e as relações sociais do país, ou por ter fixado a situação histórica brasileira por "processos sutis de arte", como quer Etienne Filho, é que pode ter prejudicado a percepção da crítica literária em relação à tensão histórica que permeia $O$ amanuense Belmiro. Pois a preponderância da preocupação com o problema sobre a preocupação com a literatura, tão comum na produção literária dos anos 30, "[...] levou por vezes a supervalorizar escritores que pareciam ter a virtude do espontâneo; e a não reconhecer devidamente obras de fatura requintada, mas desprovidas de ideologia ostensiva, como Os ratos, de Dionélio Machado (1933) ou O amanuense Belmiro, de Ciro dos Anjos (1937)".

Nesse contexto, Cyro dos Anjos parece ter internalizado a lição dada por Machado de Assis, em "Instinto de nacionalidade". Pois buscando assegurar aos autores brasileiros o direito à universalidade das matérias, em oposição ao ponto de vista que só reconhece o espírito nacional nas obras que inserem muitos nomes de flores e de aves do país, "nacionalidade de vocabulário e nada mais", ${ }^{21}$ Machado de Assis, já em 1873, advertia para os excessos nacionalistas da produção literária oitocentista. Para ele, o que liga um escritor à sua nação é "[...] certo sentimento íntimo, que o torne homem de seu tempo e de seu país, ainda quando trate de assuntos remotos no tempo e no espaço". 22

Por isso, cada um a seu tempo, ecoou como uma voz dissonante na ficção brasileira, violando o compromisso da literatura brasileira com a identidade nacional, que parece não pressupor obras e autores que se isentem de retratar o "instinto de nacionalidade", ou como quer Flora Süssekind, "não deixem traços claros de brasilidade nos seus textos". ${ }^{23}$ Sob essa perspectiva é que Cyro dos Anjos, apesar de não ter nem tematizado as classes oprimidas e desamparadas da sociedade, e nem possuir o caráter participativo tão cobrado à época, harmonizou-se ao estado de espírito crítico da ficção brasileira de 1930, fixando um momento histórico brasileiro: a coexistência de dois Brasis - um, ainda arcaico, e outro, em vias de se modernizar.

19. ETIENNE FILHO. Ao lado do amanuense, [s.p.].

20. CANDIDO. A revolução de 30 e a cultura, p. 198.

21. ASSIS. Instinto de nacionalidade, p. 141.

22. ASSIS. Instinto de nacionalidade, p. 132.

23. SÜSSEKIND. Tal Brasil, qual romance?, p. 31. 


\section{Dualidade estrutural: a marca da História}

Realizado em forma de diário, O amanuense Belmiro conta a história de seu protagonista Belmiro Borba, solteirão nostálgico e idealista, que trabalha num setor do funcionalismo público, denominado Seção de Fomento. Vivendo uma existência pouco atrativa, mas ao mesmo tempo cheia de inquietações, Belmiro encontra-se dividido entre duas épocas, o passado - representado por Vila Caraíbas, espaço da infância e da adolescência - e o presente - representado pela cidade de Belo Horizonte, espaço da vida adulta. Dessa existência morna, que se restringe ao trabalho e aos raros encontros com os amigos, o narradorpersonagem encontra uma sorte de libertação ao escrever o diário. É ele que permite, ao amanuense, racionalizar sobre os fatos da vida, chamando-o a ela.

Mas o desajuste temporal, acionado pelo choque das temporalidades - presente e passado -, impõe-lhe uma angústia permanente, que se apresenta logo nas primeiras páginas do romance. Contrariando o andamento leve e descompromissado dos dois primeiros capítulos, é no terceiro capítulo que essa duplicidade temporal se impõe e o conflito se instaura. Arrependido por ter se "metido em serenatas e outras relaxações", ${ }^{24}$ Belmiro se lamenta pela decadência da família e depois pela venda da fazenda. Filho de um grande proprietário de terras, Belmiro deixa Vila Carấbas e se muda para Belo Horizonte. Afastado definitivamente do seu passado agrário e latifundiário, é absorvido pela burocracia, graças à influência de seu pai junto a um deputado. Dado que, historicamente, põe a nu as práticas do favor que as suas origens de representante do mundo rural favoreceram-lhe apelar. Ao contrário, portanto, do tronco familiar forte e vigoroso, Belmiro considera-se um Borba errado, aquele que negara as virtudes da estirpe.

É do alpendre da sua casa na Rua Erê, na cidade de Belo Horizonte, sentado numa velha cadeira austríaca, que Belmiro leva a passear longe o pensamento, por outras ruas e por outros tempos. A revivência do passado é desencadeada, na maioria das vezes, por visões advindas do tempo atual, que trazem de volta imagens vivas da lembrança. Um comentário, uma expressão, uma música, qualquer coisa, desencadeia no personagem, num processo rememorativo, a passagem para a infância.

Vendo uma fogueira em dia de São João, Belmiro narra com nostalgia as vozes gratas da infância em que ficava até horas mortas rente ao braseiro, sob o aroma das batatas assadas, "a pensar nas terras impossíveis e

24. ANJOS. O amanuense Belmiro, p. 10. 
no destino trágico da Nau Catarineta" (p. 39), ou então, nas moças de tranças e bandós, que ficavam a ler a sorte nos copos d'água. Mas conclui com melancolia: "[...] certo São João de Vila Caraíbas é um fenômeno que não se reproduzirá jamais" (p. 39). O episódio do cego tocador de sanfona também é exemplo de como é fácil Belmiro descolar-se do seu dia a dia e transformar a Rua dos Guajajaras, em Belo Horizonte, na Ladeira da Conceição, em Vila Caraíbas, entregando-se às reminiscências.

Mas nesse esforço retrospectivo, entre as solicitações do mundo cotidiano e as impressões que a memória registrou no curso do tempo, o que perdura, afinal, na lembrança, são os arquétipos ideais de personagens e fatos que passaram fugazes nas asas do tempo. Exemplo disso é a figura de Carmélia, que encarna a namoradinha de infância, já morta, Camila, e o mito infantil, a donzela Arabela. Desse modo, as lembranças de Belmiro em relação ao mundo rural de Vila Caraíbas permanecem, sobretudo, na forma de evocação nostálgica e saudosista de um paraíso perdido.

Misturando os tempos desordenadamente, uma vez que a passagem de um tempo a outro é quase sempre súbita, Belmiro torna-se dual. A seguir, dois trechos que corroboram a existência de dois Belmiros: "Esse Absurdo de Vila Caraíbas tem uma força que supera as zombarias do Belmiro sofisticado e faz crescer desmesuradamente, em mim, um Belmiro patético e obscuro" (p. 20, grifos nossos). Ou então: "A um Belmiro patético que se expande, enorme, na atmosfera caraibana - contemplando a desvastação de suas paisagens - sempre sucede um Belmiro sofisticado, que compensa o primeiro e o retifica, ajustando-o aos quadros cotidianos" (p. 74, grifos nossos).

Verifica-se, a partir dos trechos transcritos, que há um "eu" e um "outro", um "primeiro" e, implicitamente, um "segundo". No primeiro exemplo, verifica-se que embora exista um único sujeito, ele se desdobra em dois: o Belmiro sofisticado e o Belmiro patético e obscuro. Ora, os próprios artigos, definido e indefinido, evidenciam a presença de um e de outro. Consolidando a existência do Belmiro sofisticado, o artigo definido o; já a existência do Belmiro patético e obscuro, o artigo indefinido $u m$. No segundo exemplo, além da reiterada divisão de Belmiro em dois, estabelece-se que a dicotomia está intrinsecamente associada à problemática espaço-temporal. Enquanto o Belmiro patético se expande, "enorme", na atmosfera caraibana, o Belmiro sofisticado pertence ao cotidiano belo-horizontino.

Fica evidente, portanto, que cada um deles, o patético e o sofisticado, faz parte de um tempo e de um espaço determinados. O sofisticado 
ao tempo presente e, consequentemente, a Belo Horizonte, e o patético, ao tempo passado e a Vila Caraíbas. À divisão de dois Belmiros em um só verdadeiro segue-se o confronto de duas personalidades completamente distintas, decorrente da coexistência espaço-temporal.

$\mathrm{Na}$ verdade, o zigue-zague temporal, que se desdobra num ziguezague espacial, configura-se, aos olhos de Belmiro, em um conflito permanente que há dentro de si, ocorrido no domínio espaço-temporal Ora, assim como o presente coexiste com o passado, Belo Horizonte com Vila Caraíbas, também dois Belmiros, apesar de contrários entre si, são ao mesmo tempo o analista e o lírico, o "flautista" e o amanuense.

A partir do exposto, pode-se verificar que a dualidade, seja ela espacial, temporal ou da personalidade de Belmiro, é o arcabouço sobre o qual se estrutura o romance de Cyro dos Anjos. E está nessa estrutura dual a chave para o desvendamento do caráter social assumido pela narrativa.

\section{Belo Horizonte: o Brasil em miniatura}

O que está em jogo em O amanuense Belmiro é o conflito de dois tempos históricos distintos que correspondem a espaços, valores sociais e culturais também diversos e que se formalizam, no nível estético, como irreconciliáveis para a vida do protagonista. De um lado, tem-se o tempo presente e a vida urbana e, de outro, o tempo passado e a vida rural. São as contradições e conflitos dessa diferença histórico-temporal e espacial vividos pelo sujeito-narrador que dão feição particular à linguagem desse romance, que atualiza esteticamente a coexistência de dois Brasis num só verdadeiro: o agrário e o urbano.

No nível simbólico, a representação da coexistência dessas duas formações sociais e econômicas distintas está presente no capítulo 41, intitulado "Matinada". Depois de muito tentar reconciliar-se com o sono (contra os seus hábitos, havia acordado às quatro da manhã), Belmiro se levanta: "Depois, como os bondes começassem a descer a Rua Erê, os galos iniciassem seu concerto e, finalmente, a fábrica desses indícios de vida, verifiquei a inutilidade de minhas tentativas e levantei-me resoluto. Bela antemanhã!" (p. 88).

A pé, resolve dar um passeio pela cidade. Depois de subir a Rua Erê, tomar à esquerda a Rua Diabase, que mais para o alto recebe o nome de Esmeralda, e seguir até o fim da rua para, enfim, dar no Morro dos Pintos, Belmiro observa a cidade de Belo Horizonte: 
Do alto da colina, contemplei Belo Horizonte, que apenas despertava. As cores, já vivas, do céu e a luminosa beleza da cidade feriram-me os olhos. Os edifícios suntuosos, os grandes jardins públicos, as retas avenidas, situam Belo Horizonte fora dos quadros habituais de Minas. Dentro das casas mora, porém, o mesmo e venerável espírito de Sabaraçu, Tejuco, Ouro Preto e de tantas outras vetustas cidades. (p. 88).

Do alto, Belmiro vê Belo Horizonte que nascia naquela bela manhã. Mas não é só isso que via. Do alto também constata a existência de duas realidades históricas simultâneas numa só cidade: o quadro de uma sociedade ainda arcaica, representada pelos galos que iniciavam seu matinal concerto e pelo "venerável espírito" das "vetustas cidades" mineiras, e o quadro de uma sociedade urbana, representada pela fábrica, pelo bonde, pelos seus edifícios, jardins públicos e "retas avenidas". De um lado a força e a energia modernizadoras, que "ferem" os olhos do amanuense e, de outro, a permanência de referências ou valores tradicionais. Desse modo, Belo Horizonte simboliza, metaforicamente, a coexistência entre a "nova" e a "velha" ordem brasileiras que, embora dissonantes, encontram-se justapostas.

No plano da narrativa, essa referência histórico-social brasileira é formalizada pela desarticulação espaço-temporal na linguagem de O amanuense Belmiro que, ao se desdobrar como conflito para o personagem-protagonista, configura a tensão dramática e a angústia de viver sob uma perspectiva referenciada pela experiência tradicional, rural e patriarcal, simbolizada pelo passado e por Vila Caraíbas, de um lado, e pela experiência moderna e urbana, representada pelo presente e pela cidade de Belo Horizonte, de outro lado. Nesse contexto, assim como o "pequeno mundo caraibano" que Belmiro traz dentro de si entra em choque com o "ritmo urbano" no qual o personagem leva a sua vida de amanuense, entram também as duas faces simultâneas da realidade brasileira, a agrária e a urbana.

A partir da ambiguidade estrutural apresentada, o romance capta e estiliza ficcionalmente o dinamismo histórico brasileiro, constituindo uma projeção de seu tempo, uma vez que manifesta a complexidade perturbadora de uma sociedade marcada por conflitos e desarmonias. Justamente por isso, a obra é mais do que uma construção bem feita, esteticamente bem elaborada que satisfaz em si mesma: ela é uma imagem nervosa do país. Isto é, fenômeno histórico e estético a um só tempo. 
Brazil in Miniature by Cyro dos Anjos

Abstract: Brazilian fiction of the 1930s witnessed a movement of strict ideological and literary polarization, which classified the authors as belonging to one of two stiff blocks: those who wrote social novels, and those who wrote psychological novels. Because it did not display clearly one of these two literary aesthetics, O Amanuense Belmiro (1937) by Cyro dos Anjos was promptly considered a purely intimate romance. In order to show that the author was not unaware of the problems of his own time, this article aims at highlighting the historical substractum of the novel. Keywords: Cyro dos Anjos, O Amanuense Belmiro, Critical review, Historical tension.

$$
\text { Referências }
$$

A HORA do Brasil elogia um brilhante escritor mineiro. Folha de Minas, Belo Horizonte, 3 dez. 1937.

AMADO, Milton. Impressões de um clima e dois romances. Mensagem, Belo Horizonte, maio 1938.

ANJOS, Cyro dos. Cyro aos 70. Jornal do Brasil, Rio de Janeiro, 5 out. 1976. Entrevista concedida a W. Figueiredo e L. P. Horta.

ANJOS, Cyro dos. O amanuense Belmiro. 12. ed. Rio de Janeiro: José Olympio, 1989.

ASSIS, Machado de. Instinto de nacionalidade. In: Crítica literária. São Paulo: W. M. Jackson, 1937. p. 125-146.

BERNARDES FILHO, João. O amanuense Belmiro. Minas Gerais, Belo Horizonte, [s.p.], 11 nov. 1937.

BRANDILEONE, Ana Paula F. Nobile. Cyro dos Anjos: uma nova estreia. In: CAIRO, Luiz Roberto Velloso et al. Dispersa memória: escritos sobre representação e memória na literatura brasileira. Bauru: Canal 6, 2009. p. 167-180.

CAMILlO, João. O amanuense Belmiro de Cyro dos Anjos. Voz do Norte, Diamantina, [s.p.], 24 out. 1937.

CANDIDO, Antonio. A revolução de 30 e a cultura. In: . A educação pela noite e outros ensaios. São Paulo: Ática, 1987. p. 181-198.

CYRO dos Anjos e o êxito de O amanuense Belmiro. Revista Ação, São Paulo, [s.p.], 19 dez. 1937.

ETIENNE FILHO, João. Ao lado do amanuense. O Diário, Belo Horizonte, [s.p.], 21 out. 1945.

FÁVERO, Afonso Henrique. A prosa lírica de Cyro dos Anjos. 1991. 153 f. Dissertação (Mestrado em Letras) - Faculdade de Letras, Filosofia e Ciências Humanas, Universidade de São Paulo, São Paulo, 1991. 
LIVROS Novos. Minas Gerais, Belo Horizonte, [s.p.], 26 out. 1937.

MACHADO FILHO, Aires da Mata. O amanuense Belmiro e sua novidade. Minas Gerais, Belo Horizonte, [s.p.], 8 dez. 1939.

MENDES, Oscar. A alma dos livros. O Diário, Belo Horizonte, [s.p.], 28 out. 1937.

MONT'ALVÃO, Narbal. O jornalista Cyro dos Anjos e o seu romance. Folha de Minas, Belo Horizonte, [s.p.], 11 nov. 1937.

MONTELlO, Josué. O livro nacional. Dom Casmurro, Rio de Janeiro, [s.p.], 2 dez. 1937. REBELLO, Marques. Figuras mineiras. Jornal do Comércio, Recife, [s.p.], 4 dez. 1937.

SILVA, Jair. Cyropédia. Folha de Minas, Belo Horizonte, [s.p.], 16 out. 1937.

SÜSSEKIND, Flora. Tal Brasil, qual romance? Rio de Janeiro: Achiamé, 1984.

VALLE, Antônio Motta do. Crônica do Amanuense. Revista Surto, [s.l.], [s.p.], jan. 1938.

VIANA, Heitor. O amanuense Belmiro. Touring, Rio de Janeiro, [s.p.], nov. 1937. 